\title{
CONTRIBUTION OF A FORM-FIND SHAPE OF PIN-ENDED ARCH
}

\author{
Asal Pournaghshband* \\ University of Warwick, School of Engineering, Coventry, United Kingdom
}

This paper presents the numerical application of a form-find two-pin arch shape with constant cross-section made of concrete. This investigation is carried out for arches with any span to height (L:h) ratio and any ratio of uniformly distributed load (UDL) to self-weight (SW) in which the geometry is a function of loading. The form-find arch shape is the one comprising only axial forces named momentless arch in this paper. The contribution of such a form-find arch is shown in a case study firstly through comparing its deflection with the most favourable arch shape under UDL:SW > 1 which known as parabolic form. Secondly, the first failure of arch cross-section for form-find arch is evaluated against parabolic one subjected to the same permanent load. Results show the maximum vertical displacement of the form-find arch to be almost half of the maximum vertical displacement of its parabolic equal. To have the same maximum displacement, the thickness of the form-find arch could be reduced to half of its initial value leading to mass reduction. Furthermore, the former arch shows the first cross-sectional failure for $24 \%$ higher vertical displacement at the arch crown compared to parabolic arch.

Key words: Optimal shape, Displacement, Shaping, Loads, Moments

\section{INTRODUCTION}

As a widely accepted fact, decision-making has played a major role in any field of human activity. As concerns structural design, optimization techniques facilitate the way for a designer to make a decision that achieves the highest advantage from the existing resources. Desirable forms for arches under different ratios of uniformly distributed load (UDL) to self-weight (SW) are: a parabolic arch for $U D L: S W \geq 1$, and a catenary arch for $U D L: S W<$ 1 (Pournaghshband, 2016) [01]. In the traditional procedure of designing an arch structure, the shape is determined from the outset (Curtin et al, 2006) [02]. However, this method of designing may lead to an inefficient form. Otto and Rasch described form-finding as a technique which uses optimization methods to find the optimal form under a particular load condition (Otto and Rasch, 1995) [03]. Form-finding was also defined as a technique for finding the most efficient shape of a structure under a specific load condition (Megson, 2006 and Millais, 2005) [04] and [05]. The proposed technique involves physical, numerical and mathematical modelling, that has been applied to arch structures. The developed techniques applied to two-pin arches showed the form-find shape as the momentless form.

In experimental form-finding investigation, Gaudi was well known for his novel forms of vertical and inverted catenaries (Huerta, 2006) [06]. To shape catenaries when creating a vault or natural curved arch, Gaudi hung different weights on a series of strings and then photographed the shape and inverted it to get the required form. The stability of catenary arches subjected to SW only that can transfer only axial forces was explored at the University of Stuttgart (Tomlow et al, 1989) [07]. Catenary arches subjected to SW only known as momentless form showed great stability while being rocked in their experimental investigation (Megson, 2006 and Millais, 2005) [03] and [04].

Inspired by physical hanging models, Kilian and Ochsendorf applied a well-known programme named the particle-spring system to find a funicular form that could transmit axial forces only (Kilian and Ochsendorf, 2005) [08]. They used an iterative solver to find the equilibrium state of each mass. Thus the optimal structural form was achieved once the whole system was in equilibrium.

One of the early analytical studies into optimisation of arches was carried out by Tadjbakhsh and Farshad. They investigated the possibility of optimal shape of funicular arches, when both the bending moment and shear forces are zero, and their stability. However, the general shape of the arch was defined from the beginning in their study (Tadjbakhsh and Farshad, 1973) [09]. Moving toward form-finding of arches, Farshad obtained different parametric functions for the shape of an optimal arch under static loading, defining multiple objectives (Farshad, 1976) [10]. The objectives in his research compromised minimising arch length, arch thrust, and volume of the arch material separately. Consequently, the shape of the arches with minimum thrust and minimum length was found individually when arches were of constant cross-section. In the case of arches with a variable cross section, the objectives were minimising thrust and volume of arch material respectively. Later on, Tadjbakhsh obtained the geometry of a momentless arch subjected to the SW and the superstructure load assuming constant axial stress for arches with variable cross-section (Tadjbakhsh, 1981) [11]. Tadjbakhsh showed that the arch shape was independent of the magnitude of the loading in the case of uniformly distributed load. However, the cross-sectional area varied proportional to loading. Following, Serra proposed analytical and numerical approximate solutions for the optimal form 
of funicular arches as a uniformly compressed structure (Serra, 1994) [12]. Serra found the shape of the arch with variable cross-section subjected to uniform horizontal and vertical loading analytically. It was assumed that the height to span ratio is a minimum in the analytical solution, while the limit for this ratio was not given. Afterwards, Lewis presented mathematical model of the two-pin rigid concrete arch with constant cross-section (Lewis, 2016) [13]. She applied zero shear force criterion to arches when solving equations of equilibrium for any arbitrary node on the arch. The validity of the resultant formulation was demonstrated by deriving two classical momentless arch forms such as; catenary and parabolic arch in the case of applying SW only and UDL only load condition respectively. The process of finding the geometry of this optimal arch shape was coded in MATLAB by the author for arches of any $L: h$ ratio and any ratio of UDL:SW and listed in the Appendix.

The shape of the momentless arch was found in the literature. But, the applicability of this form-find arch shape concerning its deflection and first cross-sectional failure has not been demonstrated. This paper illustrates the advantages of form-find arch over the best arch shape when UDL:SW $>1$ which is of a parabolic form, numerically. In this regard, the preference of using the form-find arch is shown through comparing its maximum deflection and first failure of the arch cross-section with those for the parabolic arch when $L: h$ ratio is 3 . The geometry difference of parabolic and form-find arch was found to be negligible in practical terms, see Table A. However, the deflection pattern of them differs significantly with the twice greater maximum vertical displacement for parabolic arch. Moreover, form-find arch could carry $5 \%$ greater load before reaching the first cross-sectional failure compared to its parabolic rival.

\section{OPTIMALITY CRITERION OF FORM-FIND ARCH}

Small changes in the shape of arches have an extensive effect on structural response (Pournaghshband, 2016) [01]. One of the most dominant structural action effects in arches is bending moment, and decreasing its magnitude leads to a smaller stress distribution, deflection and shear forces. By reducing the bending moment, an arch can resist loading by developing mostly compressive forces. Since arch structures are diagnosed as compressive ones, momentless arch form is considered as the optimal form in this study. Furthermore, in theory, a parabolic arch is momentless if it is subjected to UDL only and the $S W$ is ignored, while a catenary arch is considered as momentless once subjected to SW only (Millais, 2005) [05]. As stated earlier, parabolic and catenary arches for separately UDL only and SW only load conditions are momentless and optimal forms. For any other loading conditions, the existence of bending moments is inevitable for known shape of arches. However, obtaining an optimal form for each probable load case is not feasible, momentless arches could be derived by using a form-finding technique for different ratios of UDL:SW. The derived optimal arch shape using form-finding approach is called form-find arch here.

\section{PROJECT DESCRIPTION}

To compare the structural response of the form-find arch with known shapes of arches, a concrete arch bridge is chosen and analysed. The analysis is carried out for a hypothetical bridge with some of the basic dimensions that are taken from a concrete arch-bridge traffic overpass in Daugavpils in Latvia (Taurenis et al, 2013) [14]. This bridge is a carriageway with a parabolic shape and was constructed in 2011 to improve the transportation infrastructure. The span of the arch $(L)$ is $60 \mathrm{~m}$ and to have a more pronounced difference between the geometries of the parabolic and the form-find arch, the $L: h$ ratio is assumed to be equal to 3 , e.g., the height of the arch $(h)$ is $20 \mathrm{~m}$. It is assumed that the bridge is of a two-pin arch with a constant cross-section (depth of $0.65 \mathrm{~m}$ ) being sufficiently rigid. The arch bridge is made of $\mathrm{C} 50 / 60$ concrete with a covering of asphalt concrete for both carriageway and sidewalks. The specific weights of steel and concrete are taken as 78 and $25 \mathrm{kN} / \mathrm{m}^{3}$, respectively. The general shape of the arch is given in Figure 1.

It is seen in Figure 1 that the deck is linked to the arch rib with the support of piers (vertical members). To avoid large bending moments, the vertical members are assumed to be flexible. For this reason, to have enough flexibility in the longitudinal direction, the piers are linked to the deck and arch rib using hinge connections. The loading configuration is estimated based on EN1991-2: 2003 for a highway bridge in a harsh urban environment. According to EN1990: 2000, the factored weight of the arch (SW) is calculated equal to 110.1 $\mathrm{kN} / \mathrm{m}$. The accumulated loads applied from the weight of the deck and piers with the load from traffic passing over the deck are estimated as a total UDL of 507 $\mathrm{kN} / \mathrm{m}$ applied to the arches in this study. Consequently, the ratio of UDL:SW is 4.6 and the behaviour of the best known shape of arch, that is, a parabolic arch, is compared with the form-find arch for this loading configuration. Followed by, the $x$ and $y$ coordinates for the parabolic arch are obtained using the arch governing equation, $y=4 h / L\left(x-x^{2} / L\right)$, setting the left arch support as its origin and the arch crown passes through $(L / 2$, h). The parabolic arch is then analysed with SAP 2000, where the arch is modelled using straight elements such as beams using this $F E$ analysis software. To find the required number of nodes for modelling the arch bridge, a sensitivity analysis is carried out for the maximum bending moment of the arch with the described specification. The results of the maximum bending moment when parabolic arch is modelled with number of nodes involving: $33,43,53,63,73,83,93,103,113$, and 123 shows that the percentage difference between the maximum sagging bending moments of the arch modelled with 63 and 33 nodes is $12 \%$. The percentage difference between the maximum sagging 


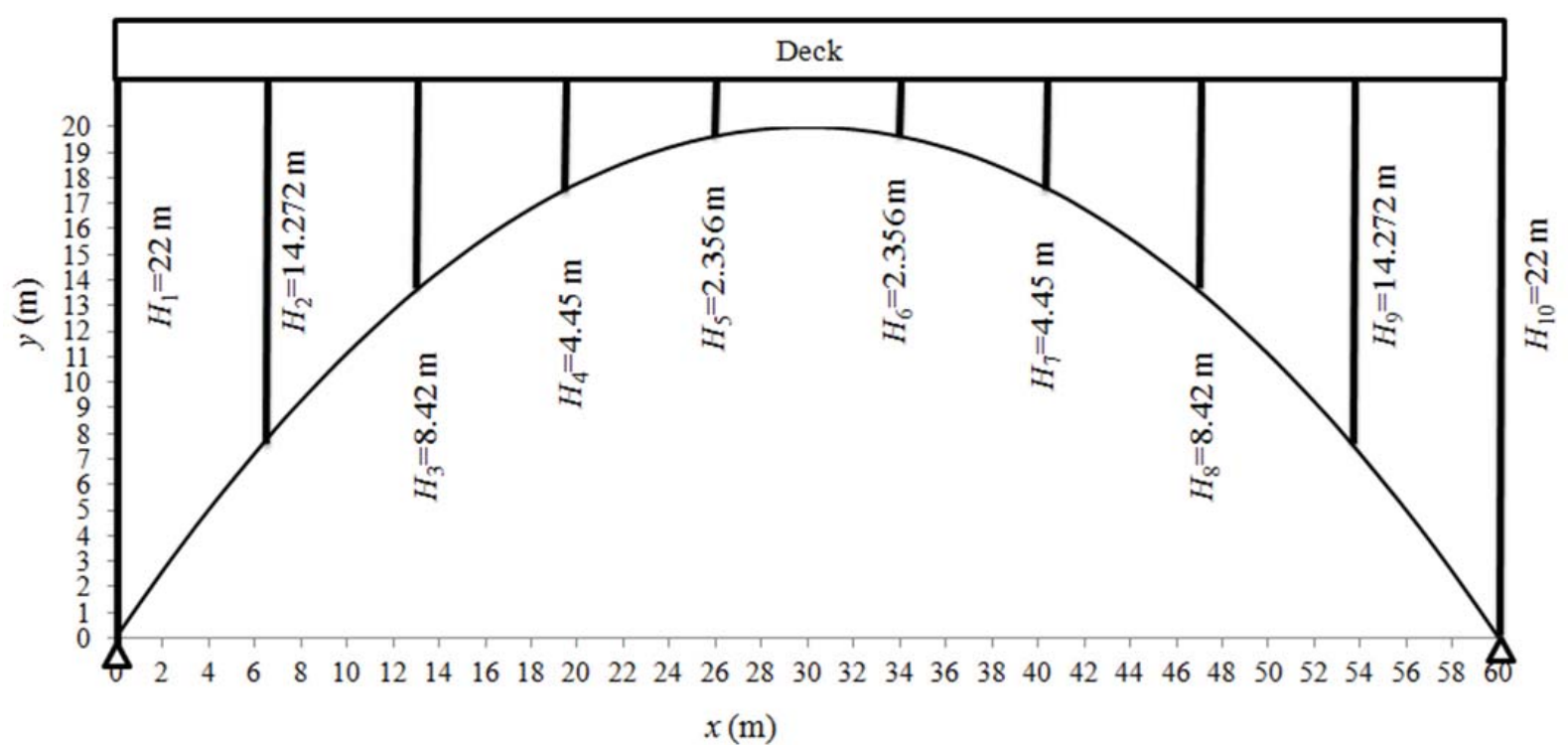

Figure 1: Shape of the studied arch bridge

bending moments of the arch modelled with 63 and 103 nodes decreased to $2.88 \%$. Then, increasing the number of nodes from 103 to 113 nodes caused the maximum sagging bending moment to decrease by $0.47 \%$, which can be considered negligible. Therefore, the trend of the change in maximum bending moment becomes roughly a straight horizontal line when the arch is modelled with more than 103 nodes. Here, 103 nodes or 102 straight elements are chosen to model the arches.

The coordinates for the form-find arch is derived from the MATLAB file listed in the Appendix. Consequentlythe, the coordinates of parabolic and form-find arch for the half span ( $n$ denotes the node number for half of arch span and is equal to 52) are given in Table $A$ in the Appendix. It is seen from Table $A$ that the maximum differences in the geometry of parabolic and form-find arch are related to a node with about $7 \%$ and $5 \%$ difference in the $x$ and $y$ coordinates respectively. Although the differences between the geometry of these arches are insignificant in practice, the theoretical precision is of importance when analysing arch behaviour. Thus, the structural response of the form-find arch is assessed against parabolic one with difference in their shapes less than $10 \%$.

\section{COMPARING THE DEFLECTION OF THE PARABOLIC AND FORM-FIND ARCH}

To compare the deflection of the parabolic arch with that of the form-find one, it is assumed that both arches are of the same material and have similar general properties. Both arches are subjected to the general combination of $U D L=507 \mathrm{kN} / \mathrm{m}$ plus $S W$. The self-weight of the two arches are assumed to be the same and equal to $110.1 \mathrm{kN} / \mathrm{m}$. Then the parabolic and form-find arches are modelled in SAP 2000. The deflections of the parabolic and form-find arches are shown in Figure 2.

The thin line represents the original shape of the arch and thick line is for the deformed shape. It can be seen that the form-find arch deforms vertically and maintains its original geometric shape under the applied load. The maximum displacement of form-find arch is seen at its crown equal to - $8 \mathrm{~mm}$. However, parabolic arch deforms noticeably with the maximum displacements equal to $15 \mathrm{~mm}$ at both sides of the arch. The maximum vertical displacement of the form-find arch is about half of that of the parabolic one. In order to have the same vertical displacement with the form-find and the parabolic arches, the thickness of the cross-section of the form-find arch is decreased gradually. The required thickness is that when the maximum displacement in the $z$ direction reaches $15 \mathrm{~mm}$ is chosen. Table 1 reports the vertical displacements $(u)$ for form-find arch having different thicknesses (d) decreased from 0.65 to $0.35 \mathrm{~m}$.

Table 1: Maximum displacements of form-find arch obtained from SAP 2000 using different arch thicknesses (d)

\begin{tabular}{|c|c|}
\hline Arch thickness $(\mathrm{m})$ & $u$ in $z$ direction $(\mathrm{mm})$ \\
\hline 0.65 & -8.205 \\
\hline 0.45 & -11.695 \\
\hline 0.40 & -13.068 \\
\hline 0.35 & -14.785 \\
\hline
\end{tabular}

As can be seen, decreasing the thickness of the form-find arch cross-section makes the maximum displacement increase. This is in accordance with the study carried out over the effect of arch geometry on the structural behaviour. (Altunişik et al, 2016) [15]. In reality the thickness of the arch should meet the minimum limit of arch thickness. Since the formfind arch is compared with the parabolic option, the former thickness can decrease without considering design regulations. It is observed that the maximum dis- 


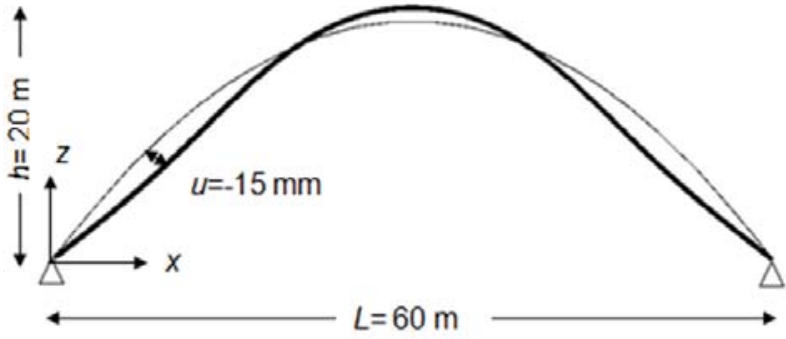

(a)

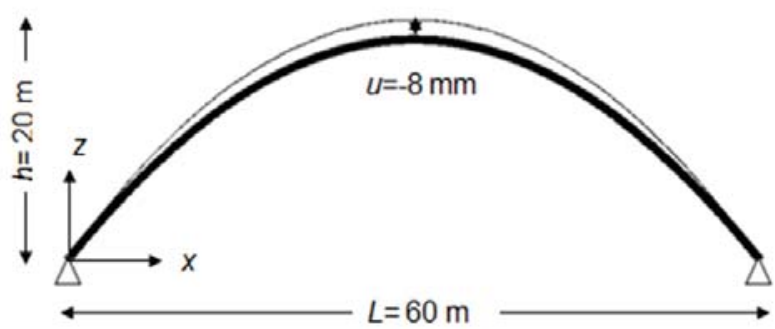

(b)

Figure 2: SAP 2000 - Deformed shape of parabolic arch

(a) and form-find arch (b) subjected to UDL of $507 \mathrm{kN} / \mathrm{m}$ plus SW of $110.1 \mathrm{kN} / \mathrm{m}$

placement in the $z$ direction for the cross-section of the form-find arch with a thickness of $0.35 \mathrm{~m}$ is close to that of the parabolic one with a thickness of $0.65 \mathrm{~m}$. Overall, the form-find arch experiences almost $50 \%$ less deflection. To have the same deflection, the form-find arch thickness for a constant rectangular cross-section can be approximately half of the thickness in the parabolic arch. It should be noted that the parabolic arch has the minimum deflection compared to circular and catenary arches for this load case.

The reduction in form-find arch thickness leads to the arch mass decrease. The form-find arch shape mass is equal to $619 \mathrm{kNs}^{2} / \mathrm{m}$ for $d=0.65 \mathrm{~m}$. To have a similar maximum vertical displacement, the form-find arch mass is reduced to $334 \mathrm{kNs}^{2} / \mathrm{m}$ with $d=0.35 \mathrm{~m}$. The mass reduction is important for the construction cost and material saving.

\section{COMPARING THE FIRST CROSS-SECTIONAL FAILURE OF THE PARABOLIC AND FORM-FIND ARCH}

One of the reasons for searching for an optimized shape of the arch is to establish greater resistance. In other words, a favourable arch structure is one that carries a specified design load case or cases for the minimum weight of the construction material. Concerning other applications of the form-find arch, the first failure of the arch section is evaluated with the first failure of the parabolic arch section. The first failure of arch cross-section is emerged under ultimate load beyond the initial yield limit.

For the first step of finding the failure of these arches, the OpenSees program (http://OpenSees.berkeley.edu/) was used. OpenSees is an interactive Tool Command Language $(T c l)$ software framework in which the commands can be changed at any time and performed at the MS-DOS/Unix prompt. This program works in parallel with MATLAB as a post-processing tool generated by means of $T C l$ scripting language. Each $\mathrm{TCl}$ command is bound with a $\mathrm{C}++$ procedure. Therefore, this finite element analysis is executed to simulate the response of the arch structure to the applied loading. Both parabolic and form-find arches are modelled using straight elements, which are defined as displacement-based beam-column ele- ments. Since this programme performs as displacement control, the displacement increased by $1 \mathrm{~mm}$ at the crown of the arch. As a result, the required structural responses are achieved at each displacement increment using OpenSees.

The second step of finding the first failure of the arch cross-section is accomplished by using an interaction curve between the axial forces and bending moments. Hence, the obtained axial forces and bending moments from OpenSees are plotted. This diagram is plotted for each displacement. To do so, a programme was written in Excel as "Visual Basic" that only requires a vertical displacement at the arch crown as input and gives a diagram of the axial force and bending moment for that displacement. The interaction curve of the arch cross-section can be plotted based on finding some points on the curve such as, the points relevant to the squash load, decompression, balance, and pure moment (EN1992-1-1:2004). These points are calculated using dimension, reinforcement, and material properties of the cross-section for each arch. The generated interaction curve of each arch is then plotted on the same diagram of axial force and bending moments. To have a safe cross-section, the diagram of axial forces and bending moments of the arch must be under the interaction curve of the arch cross-section. Therefore, the displacement at which the diagram of axial forces and bending moments from OpenSees crosses the interaction curve of the cross-section is considered as the first failure of the cross-section. The parabolic arch shows the first failure of the cross-section when the vertical displacement at the arch crown is $3950 \mathrm{~mm}$; see Figure 3. Meanwhile, from Figure 4, the first failure of the cross-section of the form-find arch is seen for a vertical displacement of $5200 \mathrm{~mm}$ at the arch crown. This shows that first failure of form-find arch cross-section is occurred for $24 \%$ higher vertical displacement at arch crown than parabolic shape.

The green, purple, and blue straight lines in Figures 3 and 4 connect the minimum eccentricity, decompression, and nominal balance points to the origin. The minimum eccentricity point shows the maximum moment strength at the maximum axial compression load permitted by Eurocode. The decompression point shows 
compression and moment strength at zero strain in the tension side reinforcement. The nominal balance point presents compression and moment strength at $50 \%$ strain in the tension side reinforcement. The interaction curve crosses the axial force axis at the squash load point that gives the axial compression at zero moment.

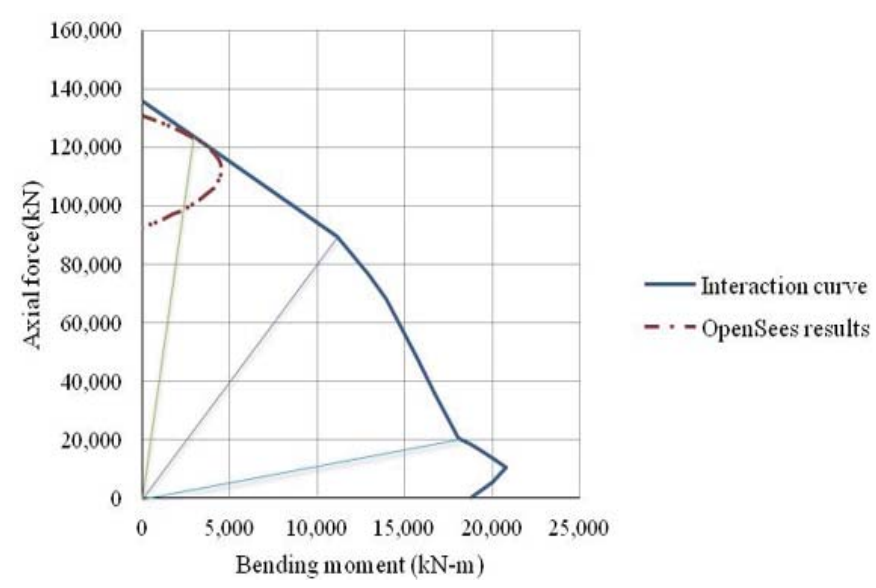

Figure 3: Comparison of the interaction curve of the parabolic arch cross-section and diagram

of the axial force and bending moment results from

OpenSees when the vertical displacement at the arch crown is $3950 \mathrm{~mm}$

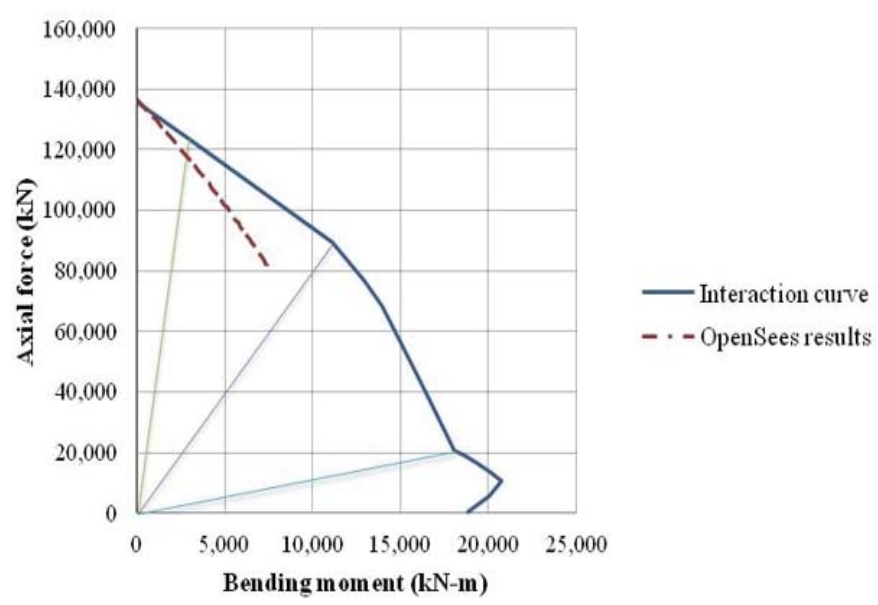

Figure 4: Comparison of the interaction curve of the form-find arch cross-section and diagram of axial force and bending moment results from OpenSees when the vertical displacement at the arch crown is $5200 \mathrm{~mm}$

The interaction curve also crosses the bending moment axis at pure moment point when the axial force is zero.

Although the interaction curve of the parabolic arch is similar to that of the form-find arch, the axial force and bending moment diagrams from OpenSees are completely different for these two arches. According to the OpenSees results, the total load that causes first failure of the parabolic arch is $211992 \mathrm{kN}$. First failure of the form-find arch is initiated at $221722 \mathrm{kN}$. Comparing the first failures of the parabolic and form-find arches, the latter one could carry $5 \%$ higher load before reaching the first cross-sectional failure.

\section{CONCLUDING REMARKS}

The advantages of using the form-find arch was shown numerically by comparing its deflection and first cross-sectional failure with those obtained for a parabolic arch in a theoretical case study. This exploration was carried out for $U D L: S W>1$. Since the parabolic arch performed best for this load case against catenary or circular arch shape: the form-find arch compared to the best-known arch shape. The studied arches were considered rigid with constant cross-section. They were also assumed to be made of concrete material which is relatively weak in tension subjected to the same loading for $L: h=3$.

Case study shows that the parabolic arch deformed significantly, while the form-find arch kept its geometry. The maximum displacement of the parabolic arch to be about twice greater that of the maximum displacement of form-find arch for a similar load case. To have the same maximum displacement, the thickness of the form-find arch could be reduced to half of its initial value. This leads to mass reduction in the case of form-find arch to about half on its initial mass which affect construction cost noticeably.

From case study, form-find arch could carry $5 \%$ greater load before reaching the first cross-sectional failure compared to the parabolic form under the same conditions. The form-find arch shows this first failure for $24 \%$ higher vertical displacement at the arch crown compared to the parabolic one.

Overall, the comparison confirmed the superiority of using the form-find arch in practice which demonstrates the significant effect of shape on structural response.

\section{REFERENCES}

1. Pournaghshband A, (2016). Form-finding of arch structures. U . Warwick, UK: University of Warwick.

2. Curtin WG. Shaw G. Beck JK. Bray WA, (2006). Structural Masonry Designers' Manual, 3rd. Massachusetts, USA: Blackwell Publishing Inc..

3. Otto F. Rasch B, (1995). Finding Form: Towards an Architecture of the Minimal, 3rd. Deutsche Werkbund Bayen: Axel Menges,

4. Megson T H G, (2006). Structural and Stress Analysis, 2nd. Oxford, UK: Elsevier.

5. Millais M, (2005). Building Structures: From concepts to design, 2nd. Abingdon, UK: Spon Press.

6. Huerta $S,(2006)$. Structural Design in the Work of Gaudi. Architectural Science Review, 45(4), 324339.

7. Tomlow J. Graefe R. Otto F. Szeemann H, (1989). Das Modell / The Model / El Modelo. Stuttgart, Germany: Institut für Leichte Flächentragwerke.

8. Killian A. Ochsendorf J, (2005). Particle-Spring Systems for Structural Form Finding. Journal of the International Association for Shell and Spatial Structures, 46(2), 77-84. 
9. Tadjbakhsh IG. Farshad M, On conservatively loaded funiular arches and their optimal design. U: Proceedings of IUTAM Symposium on Optimization in Structural Design, 1973, Warsaw.

10. Farshad M, (1976). On optimal form of arches. Journal of the Franklin Institute, 302(2), 87-194.

11. Tadjbakhsh IG, (1981). Stability and optimum design of arch-type structures. International Journal of Solids \& Structures, 17(6), 565-574.

12. Serra M, (1994). Optimal Arch: Approximate Analytical and Numerical Solutions. The Royal Society, 52(6), 1213-1220

13. Lewis WJ, (2016). Mathematical model of a moment-less arch. Computer Structures, 472(2190).

14. Taurenis M. Linde A. Gruberts R. Straupe V, Examples of construction of new reinforced concrete arch bridges in Latvia. U: XXVIII International Baltic Road Conference, 2013, Lithuania.

15. Altunişik AC. Kanbur B. Genç AF, (2016). The effect of arch geometry on the structural behavior of masonry bridges. Smart Structures and Systems, 16(6), 1069-1089.

\section{APPENDIX}

By choosing a number of required nodes $(n)$ on the half of the arch (from left support to the mid span), $L: h$ ratio, and loading ( $w=U D L$ and $q=S W$ ), the $x$ and $y$ of each node is given using the listed code below. Also, the shape of the half of the arch is plotted in this programme. The bold letters indicate the input values. This programme is written for any $L: h$ ratio and any ratio of UDL:SW.

$\mathbf{n}=; \%$ (number of nodes for half span of the arch)

$\mathbf{L}=$;

$\mathbf{h}=$;

$r=\mathrm{L} / \mathrm{h}$;

w = UDL;

$\mathbf{q}=\mathbf{S W}$;

$\mathrm{k}=\mathrm{UDL} / \mathrm{SW}$;

if $\left(\mathrm{k}^{\wedge} 2\right)<1$

$\mathrm{A}=3$;

$\mathrm{y} 1=0$;

$\mathrm{x} 1=0$;

$\mathrm{L}=10$;

$\mathrm{h}=5$;

$r=L / h$

for $\mathrm{i}=1: 100$

$\mathrm{b}=\mathrm{A}$;

$F=y 1-h+b^{*} \cosh ((L / 2) / b)-b$;

$\mathrm{F} 1=\cosh ((\mathrm{L} / 2) / \mathrm{b})-\left(\left((\mathrm{L} / 2)^{*} \sinh ((\mathrm{L} / 2) / \mathrm{b})\right) / \mathrm{b}\right)-1$;

$A=b-(F / F 1)$;

$\mathrm{i}=\mathrm{i}+1$; if $\operatorname{abs}(\mathrm{F} / \mathrm{F} 1)<0.00000000001$;

break

end

end

i

format long

A

$\operatorname{tmax} 0=\sinh \left(L /\left(2^{*} A\right)\right)$

syms tmax;

$\mathrm{Ft}=\left(\operatorname{asinh}(\operatorname{tmax})+\left(\mathrm{k} /\left(1-\mathrm{k}^{\wedge} 2\right)^{\wedge}(0.5)\right)^{*}\left(\operatorname{atan}\left(\operatorname{tmax}{ }^{*} \mathrm{k} /\right.\right.\right.$ $\left.\left(\left(1+\operatorname{tmax}{ }^{\wedge} 2\right)^{\wedge}(0.5)^{*}\left(1-k^{\wedge} 2\right)^{\wedge}(0.5)\right)\right)-\operatorname{atan}(\operatorname{tmax} /(1-$ $\left.\left.\left.\left.\mathrm{k}^{\wedge} 2\right)^{\wedge}(0.5)\right)\right)\right) /\left(\left(1+\operatorname{tmax}^{\wedge} 2\right)^{\wedge}(0.5)-1+\mathrm{k}^{\star} \log ((\mathrm{k}+1) /(\mathrm{k}+(1+\mathrm{t}-\right.$ $\left.\left.\left.\max ^{\wedge} 2\right)^{\wedge}(0.5)\right)\right)$;

options = optimset ('TolX',1e-18);

[tmax exitflag output] = fzero(@(tmax)eval $(\mathrm{r} / 2-\mathrm{Ft})$, tmax0 ,options);

tmax

$\mathrm{H}=\left(\mathrm{q}^{*} \mathrm{~h}\right) /\left(\mathrm{k}^{*} \log \left((\mathrm{k}+1) /\left(\mathrm{k}+\left(1+\operatorname{tmax}^{\wedge} 2\right)^{\wedge}(0.5)\right)\right)+(1+\right.$ $\left.\operatorname{tmax} 2)^{\wedge}(0.5)-1\right)$

for $i=2: n+1$;

tsash $=\operatorname{tmax} /(n)$

$\mathrm{t} 0=\mathrm{tmax}$

$t(1)=t$ max - tsash

$\mathrm{t}(\mathrm{i})=\mathrm{t}(\mathrm{i}-1)-\mathrm{tsash}$

\%Then for $n$ number of nodes, $n x$ and $y$ should be found for each $t$... means to has $x=0$ and $y=0$ from below equations and $t 1 \ldots$

$\mathrm{x}(1)=(-\mathrm{H} / \mathrm{q})^{*}\left(\operatorname{asinh}(\mathrm{t} 0)+\left(\mathrm{k} /\left(1-\mathrm{k}^{\wedge} 2\right)^{\wedge}(0.5)\right)^{*}\left(\operatorname{atan}\left(\mathrm{t} 0^{*} \mathrm{k} /\right.\right.\right.$

$\left.\left(\left(1+\mathrm{t} 0^{\wedge}(2)\right)^{\wedge}(0.5)^{\star}\left(1-\mathrm{k}^{\wedge} 2\right)^{\wedge}(0.5)\right)\right)-\operatorname{atan}(\mathrm{t} 0 /$

$\left.\left.\left.\left(1-\mathrm{k}^{\wedge} 2\right)^{\wedge}(0.5)\right)\right)\right)+(\mathrm{L} / 2)$;

$\mathrm{y}(1)=(-\mathrm{H} / \mathrm{q}) *\left(\left(1+\mathrm{t} 0^{\wedge}(2)\right) \wedge(0.5)-1+\mathrm{k} * \log ((\mathrm{k}+1) /\right.$

$\left.\left.\left(\mathrm{k}+\left(1+\mathrm{t} 0^{\wedge} 2\right)^{\wedge}(0.5)\right)\right)\right)+\mathrm{h}$;

$\mathrm{x}(\mathrm{i})=(-\mathrm{H} / \mathrm{q})^{*}\left(\operatorname{asinh}(\mathrm{t}(\mathrm{i}-1))+\left(\mathrm{k} /\left(1-\mathrm{k}^{\wedge} 2\right)^{\wedge}(0.5)\right)^{*}(\operatorname{atan}(\mathrm{t}(\mathrm{i}-\right.$ $\left.1)^{\star} \mathrm{k} /\left(\left(1+\mathrm{t}(\mathrm{i}-1)^{\wedge}(2)\right)^{\wedge}(0.5)^{\star}\left(1-\mathrm{k}^{\wedge} 2\right)^{\wedge}(0.5)\right)\right)-\operatorname{atan}(\mathrm{t}(\mathrm{i}-1) /$ $\left.\left.\left.\left(1-\mathrm{k}^{\wedge} 2\right)^{\wedge}(0.5)\right)\right)\right)+(\mathrm{L} / 2)$;

$\mathrm{y}(\mathrm{i})=(-\mathrm{H} / \mathrm{q})^{*}\left(\left(1+\mathrm{t}(\mathrm{i}-1)^{\wedge}(2)\right)^{\wedge}(0.5)-1+\mathrm{k}^{*} \log ((\mathrm{k}+1) /(\mathrm{k}+(1+\mathrm{t}(\mathrm{i}-\right.$ $\left.\left.\left.\left.1)^{\wedge} 2\right)^{\wedge}(0.5)\right)\right)\right)+\mathrm{h}$;

$\mathrm{i}+1$;

format short

$\operatorname{disp}(\mathrm{x})$

$\operatorname{disp}(y)$

plot $\left(\mathrm{x}, \mathrm{y}, \mathrm{r}^{\prime}\right)$

end

else

if $\mathrm{k}^{\wedge} 2>1$

$\operatorname{tmax} 0=4 / r$;

syms tmax;

$\mathrm{Ft}=\left(\operatorname{asinh}(\operatorname{tmax})+\left(\mathrm{k} /\left(\mathrm{k}^{\wedge} 2-1\right)^{\wedge}(0.5)\right) *(-\operatorname{atanh}(\mathrm{tmax}\right.$ *

$\left.\mathrm{k} /\left(\left(1+\operatorname{tmax}^{\wedge} 2\right)^{\wedge}(0.5)^{*}\left(\mathrm{k}^{\wedge} 2-1\right)^{\wedge}(0.5)\right)\right)+$ atanh $\left.\left.\left(\operatorname{tmax} /\left(\mathrm{k}^{\wedge} 2-1\right)^{\wedge}(0.5)\right)\right)\right) /\left(\left(1+\operatorname{tmax}^{\wedge} 2\right)^{\wedge}(0.5)-1+\right.$ 
$\left.\mathrm{k}^{*} \log \left((\mathrm{k}+1) /\left(\mathrm{k}+\left(1+\operatorname{tmax}^{\wedge} 2\right)^{\wedge}(0.5)\right)\right)\right)$

options= optimset('TolX',1e-18);

[tmax exitflag output] = fzero $(@($ tmax $)$ eval $(r / 2$ - Ft $)$, tmax0,options);

tmax

$\mathrm{H}=\left(\mathrm{q}^{*} \mathrm{~h}\right) /\left(\mathrm{k} * \log \left((\mathrm{k}+1) /\left(\mathrm{k}+\left(1+\operatorname{tmax}^{\wedge} 2\right)^{\wedge}(0.5)\right)\right)\right.$ $\left.+\left(1+\operatorname{tmax}^{\wedge} 2\right)^{\wedge}(0.5)-1\right)$

for $\mathrm{i}=2: \mathrm{n}+1$;

tsash $=\operatorname{tmax} /(n)$

$\mathrm{t} 0=\mathrm{tmax}$

$\mathrm{t}(1)=\mathrm{tmax}-\mathrm{tsash}$

$\mathrm{t}(\mathrm{i})=\mathrm{t}(\mathrm{i}-1)-\mathrm{tsash}$

\%Then for $n$ number of nodes, $n x$ and $y$ should be found for each $t$... means to has $x=0$ and $y=0$ from below equations and $11 . .$.

$\mathrm{x}(1)=(-\mathrm{H} / \mathrm{q})^{*}\left(\operatorname{asinh}(\mathrm{t} 0)+\left(\mathrm{k} /\left(\mathrm{k}^{\wedge} 2-1\right)^{\wedge}(0.5)\right) *(\right.$ $-\operatorname{atanh}\left(\mathrm{tO} * \mathrm{k} /\left(\left(1+\mathrm{t0}{ }^{\wedge}(2)\right)^{\wedge}(0.5)^{*}\left(\mathrm{k}^{\wedge} 2-1\right)^{\wedge}(0.5)\right)\right)+$ atanh $\left.\left.\left(\mathrm{tO} /\left(\mathrm{k}^{\wedge} 2-1\right)^{\wedge}(0.5)\right)\right)\right)+(\mathrm{L} / 2)$;

$\mathrm{y}(1)=(-\mathrm{H} / \mathrm{q}) *\left(\left(1+\mathrm{t} 0^{\wedge}(2)\right) \wedge(0.5)-1+\mathrm{k} * \log ((\mathrm{k}+1)\right.$

$\left.\left./\left(\mathrm{k}+\left(1+\mathrm{t} 0^{\wedge} 2\right)^{\wedge}(0.5)\right)\right)\right)+\mathrm{h}$;

$\mathrm{x}(\mathrm{i})=(-\mathrm{H} / \mathrm{q}){ }^{*}\left(\operatorname{asinh}(\mathrm{t}(\mathrm{i}-1))+\left(\mathrm{k} /\left(\mathrm{k}^{\wedge} 2-1\right)^{\wedge}(0.5)\right)^{*}\right.$ $\left(-\operatorname{atanh}(\mathrm{t}(\mathrm{i}-1))^{*} \mathrm{k} /((1+\mathrm{t}(\mathrm{i}-1) \wedge(2)) \wedge(0.5))^{*}\left(\mathrm{k}^{\wedge} 2-1\right)^{\wedge}\right.$ $\left.\left.(0.5)))+\operatorname{atanh}\left(\mathrm{t}(\mathrm{i}-1) /\left(\mathrm{k}^{\wedge} 2-1\right)^{\wedge}(0.5)\right)\right)\right)+(\mathrm{L} / 2)$;

$\mathrm{y}(\mathrm{i})=(-\mathrm{H} / \mathrm{q})^{*}\left(\left(1+\mathrm{t}(\mathrm{i}-1)^{\wedge}(2)\right)^{\wedge}(0.5)-1+\mathrm{k} * \log ((\mathrm{k}+\right.$ 1) $\left.\left./\left(\mathrm{k}+\left(1+\mathrm{t}(\mathrm{i}-1)^{\wedge} 2\right)^{\wedge}(0.5)\right)\right)\right)+\mathrm{h}$;

$\mathrm{i}+1$;

format short

$\operatorname{disp}(x)$

$\operatorname{disp}(y)$

$\operatorname{plot}\left(\mathrm{x}, \mathrm{y},{ }^{\prime} b^{\prime}\right)$

end

else $\%$ if $\left(\mathrm{k}^{\wedge} 2\right)=1$

$\operatorname{tmax} 0=4 / r$;

syms tmax;

$\mathrm{Ft}=\left((1 / \mathrm{tmax}) *\left(\left(1+\operatorname{tmax}^{\wedge} 2\right)^{\wedge}(0.5)-\mathrm{tmax} * \operatorname{asinh}(\mathrm{t}-\right.\right.$ $\max )-1)) /\left(1-\left(1+\operatorname{tmax}^{\wedge} 2\right)^{\wedge}(0.5)+\log ((1+(1+\operatorname{tmax}\right.$ $\wedge$ 2)^ (0.5)) / 2))

options= optimset('TolX',1e-18);

$[$ tmax exitflag output $]=$ fzero $(@($ tmax $)$ eval $(\mathrm{r} / 2$ - Ft $)$, tmax0,options);

tmax

$\mathrm{H}=\left(\mathrm{q}^{*} \mathrm{~h}\right) /\left(-\log \left(\left(1+\left(1+\operatorname{tmax}^{\wedge} 2\right)^{\wedge}(0.5)\right) / 2\right)+\left(1+\operatorname{tmax}^{\wedge} 2\right)^{\wedge}\right.$

$(0.5)-1)$

for $\mathrm{i}=2: \mathrm{n}$;

tsash $=\operatorname{tmax} /(n)$

t0 $=$ tmax

$\mathrm{t}(1)=\mathrm{tmax}-\mathrm{tsash}$

$\mathrm{t}(\mathrm{i})=\mathrm{t}(\mathrm{i}-1)-\mathrm{tsash}$

$\%$ Then for $n$ number of nodes, $n x$ and $y$ should be found for each $t . .$. means to has $x=0$ and $y=0$ from below equations and 11 .

$\mathrm{x}(1)=(\mathrm{H} / \mathrm{q}){ }^{*}\left((1 / \mathrm{t} 0)^{*}\left(\left(1+\mathrm{t} 0^{\wedge} 2\right) \wedge(0.5)-\mathrm{t} 0\right.\right.$ * $\operatorname{asinh}(\mathrm{t} 0)$

$-1))+(L / 2)$

$\mathrm{y}(1)=(\mathrm{H} / \mathrm{q}){ }^{*}\left(\log \left(\left(1+\left(1+\mathrm{t} 0^{\wedge} 2\right)^{\wedge}(0.5)\right) / 2\right)+1-(1\right.$ + to $\wedge$ 2)^ $(0.5))+h$;

$\mathrm{x}(\mathrm{i})=(\mathrm{H} / \mathrm{q})^{*}\left((1 / \mathrm{t}(\mathrm{i}-1))^{*}\left(\left(1+\mathrm{t}(\mathrm{i}-1)^{\wedge} 2\right)^{\wedge}(0.5)-\mathrm{t}(\mathrm{i}-1)\right.\right.$

$* \operatorname{asinh}(\mathrm{t}(\mathrm{i}-1))-1))+(\mathrm{L} / 2)$

$\mathrm{y}(\mathrm{i})=(\mathrm{H} / \mathrm{q})^{*}\left(\log \left(\left(1+\left(1+\mathrm{t}(\mathrm{i}-1)^{\wedge} 2\right)^{\wedge}(0.5)\right) / 2\right)+1-(1\right.$ $\left.\left.+\mathrm{t}(\mathrm{i}-1)^{\wedge} 2\right)^{\wedge}(0.5)\right)+\mathrm{h}$;

$\mathrm{i}+1$;

format short

$\operatorname{disp}(x)$

$\operatorname{disp}(\mathrm{y})$

plot(x,y,'g')

end

end

end 
Table A: Coordinates of parabolic and form-find arch for the half span

\begin{tabular}{|c|c|c|c|c|c|c|c|c|c|}
\hline \multirow{3}{*}{$\begin{array}{l}n \\
1\end{array}$} & \multicolumn{2}{|c|}{ Parabolic arch } & \multicolumn{2}{|c|}{ Form-find arch } & \multirow{3}{*}{$\begin{array}{c}n \\
27\end{array}$} & \multicolumn{2}{|c|}{ Parabolic arch } & \multicolumn{2}{|c|}{ Form-find arch } \\
\hline & $x(\mathrm{~m})$ & $y(\mathrm{~m})$ & & $y(m)$ & & & $y(\mathrm{~m})$ & & $y(m)$ \\
\hline & 0.00 & 0.00 & 0.00 & 0.00 & & 15.29 & 15.19 & 14.83 & 14.97 \\
\hline 2 & 0.59 & 0.78 & 0.55 & 0.74 & 28 & 15.88 & 15.57 & 15.43 & 15.36 \\
\hline 3 & 1.18 & 1.54 & 1.10 & 1.46 & 29 & 16.47 & 15.93 & 16.02 & 15.73 \\
\hline 4 & 1.76 & 2.28 & 1.65 & 2.18 & 30 & 17.06 & 16.28 & 16.62 & 16.09 \\
\hline 5 & 2.35 & 3.01 & 2.20 & 2.88 & 31 & 17.65 & 16.61 & 17.22 & 16.43 \\
\hline 6 & 2.94 & 3.73 & 2.76 & 3.57 & 32 & 18.24 & 16.92 & 17.82 & 16.76 \\
\hline 7 & 3.53 & 4.43 & 3.32 & 4.25 & 33 & 18.82 & 17.22 & 18.42 & 17.07 \\
\hline 8 & 4.12 & 5.11 & 3.87 & 4.91 & 34 & 19.41 & 17.51 & 19.02 & 17.37 \\
\hline 9 & 4.71 & 5.78 & 4.43 & 5.56 & 35 & 20.00 & 17.78 & 19.62 & 17.65 \\
\hline 10 & 5.29 & 6.44 & 5.00 & 6.20 & 36 & 20.59 & 18.03 & 20.23 & 17.92 \\
\hline 11 & 5.88 & 7.07 & 5.56 & 6.82 & 37 & 21.18 & 18.27 & 20.83 & 18.17 \\
\hline 12 & 6.47 & 7.70 & 6.13 & 7.44 & 38 & 21.76 & 18.49 & 21.44 & 18.40 \\
\hline 13 & 7.06 & 8.30 & 6.70 & 8.03 & 39 & 22.35 & 18.70 & 22.04 & 18.62 \\
\hline 14 & 7.65 & 8.90 & 7.27 & 8.62 & 40 & 22.94 & 18.89 & 22.65 & 18.83 \\
\hline 15 & 8.24 & 9.47 & 7.84 & 9.19 & 41 & 23.53 & 19.07 & 23.26 & 19.01 \\
\hline 16 & 8.82 & 10.03 & 8.41 & 9.75 & 42 & 24.12 & 19.23 & 23.87 & 19.18 \\
\hline 17 & 9.41 & 10.58 & 8.99 & 10.30 & 43 & 24.71 & 19.38 & 24.48 & 19.34 \\
\hline 18 & 10.00 & 11.11 & 9.56 & 10.83 & 44 & 25.29 & 19.51 & 25.09 & 19.48 \\
\hline 19 & 10.59 & 11.63 & 10.14 & 11.34 & 45 & 25.88 & 19.62 & 25.71 & 19.60 \\
\hline 20 & 11.18 & 12.13 & 10.72 & 11.85 & 46 & 26.47 & 19.72 & 26.32 & 19.71 \\
\hline 21 & 11.76 & 12.61 & 11.31 & 12.34 & 47 & 27.06 & 19.81 & 26.93 & 19.80 \\
\hline 22 & 12.35 & 13.08 & 11.89 & 12.81 & 48 & 27.65 & 19.88 & 27.54 & 19.87 \\
\hline 23 & 12.94 & 13.53 & 12.48 & 13.27 & 49 & 28.24 & 19.93 & 28.16 & 19.93 \\
\hline 24 & 13.53 & 13.97 & 13.06 & 13.72 & 50 & 28.82 & 19.97 & 28.77 & 19.97 \\
\hline 25 & 14.12 & 14.39 & 13.65 & 14.15 & 51 & 29.41 & 19.99 & 29.39 & 19.99 \\
\hline 26 & 14.71 & 14.80 & 14.24 & 14.57 & 52 & 30 & 20 & 30 & 20 \\
\hline
\end{tabular}

Paper submitted: 21.02.2017. 